\title{
Respiratory Failure Induced by Severe Hypothyroidism in a Korean Woman
}

\section{Hyucki Kwon, Bo Ra Kim, Seon-Sook Han, Yoonki Hong}

Department of Internal Medicine, Kangwon National University Hospital, Chuncheon, Korea

\begin{abstract}
A 76-year-old Korean woman visited to emergency room because of respiratory arrest and admitted to intensive care unit of the hospital. Severe hypothyroidism was diagnosed after repeated failure of weaning mechanical ventilator. Respiratory arrest and weaning failures were considered to be associated with hypoventilation due to hypothyroidism. She was recovered and weaned from mechanical ventilation after replacement of thyroid hormone. Severe hypothyroidism may be a cause of respiratory failure or weaning failure.
\end{abstract}

Keywords: Hypothyroidism; Respiratory insufficiency; Hypoventilation

\section{INTRODUCTION}

Respiratory involvements are sometimes occurred in patients with hypothyroidism. Dyspnea on exertion, sleep apnea, diaphragmatic dysfunction, impaired response to hypoxia and hypercapnia, and neuromuscular dysfunction have been reported [14]. Rarely, severe hypothyroidism may develop respiratory failure and can be life threatening. Literatures showed that impaired ventilatory responses to hypoxia and hypercapnia, respiratory muscle dysfunction including diaphragm, and obstructive sleep apnea episodes were associated with respiratory failure in patients with severe hypothyroidism [4-6]. Here, we report a case of elderly Korean woman who suffered from respiratory failure and weaning failure associated with hypothyroidism.

\section{CASE REPORT}

A 76-year-old woman visited to emergency room due to altered mentality of coma. She had past medical history of hypertension, diabetes mellitus, chronic heart failure, and stable angina. Her daily treatment was aspirin $100 \mathrm{mg}$, clopidogrel bisulfate $75 \mathrm{mg}$, rosuvastatin calcium $10 \mathrm{mg}$, sitagliptin phosphate hydrate $100 \mathrm{mg}$, losartan potassium $50 \mathrm{mg}$, hydrochlorothiazide $12.5 \mathrm{mg}$, and metformin hydrochloride $1,000 \mathrm{mg}$.

As soon as arrived at emergency room, she was arrested and restored after 2 minutes of cardiopulmonary resuscitation. The patient's face and extremities were edematous, and she presented with non-pitting edema. Her skin was dry, cool, pale but not has goiter, pachyglossia or myxedma. Initial arterial blood gas analysis (ABGA) showed severe respiratory acidosis ( $\mathrm{pH}$ of 7.01, $\mathrm{pCO}_{2}$ of $109.0 \mathrm{mmHg}, \mathrm{pO}_{2}$ of $40.9 \mathrm{mmHg}, \mathrm{HCO}_{3}$ of $31.9 \mathrm{mmol} / \mathrm{L}$, and oxygen saturation of 52.0\%). Chest radiography showed haziness opacities in both lungs (Fig. 1). And electrocardiography showed normal sinus rhythm with regular heart beats. Initial hemoglobin was $11.4 \mathrm{~g} / \mathrm{dL}$, white blood cell count was $15,000 / \mathrm{mm}^{3}$ (neutrophils, $80.0 \%$; lymphocytes, $13 \%$; eosinophils, $0.9 \%$ ) and platelet count was $205,000 / \mathrm{mm}^{3}$. Blood urea nitrogen/creatinine was 36.6/2.2 mg/dL. Sodium/potassium/chloride was 142/5.9/101 $\mathrm{mmol} / \mathrm{L}$. The C-reactive protein was $<0.020 \mathrm{mg} / \mathrm{dL}$, while brain natriuretic peptide was $102 \mathrm{pg} / \mathrm{mL}$. Prothrombin time was 13.8 seconds and partial thromboplastin time was 34.3 seconds. Aspartate aminotransferase/alanine transaminase was 66/34 U/L.

She was admitted to intensive care unit and get ventilator and extracorporeal membrane oxygenation (ECMO) support. Chest 


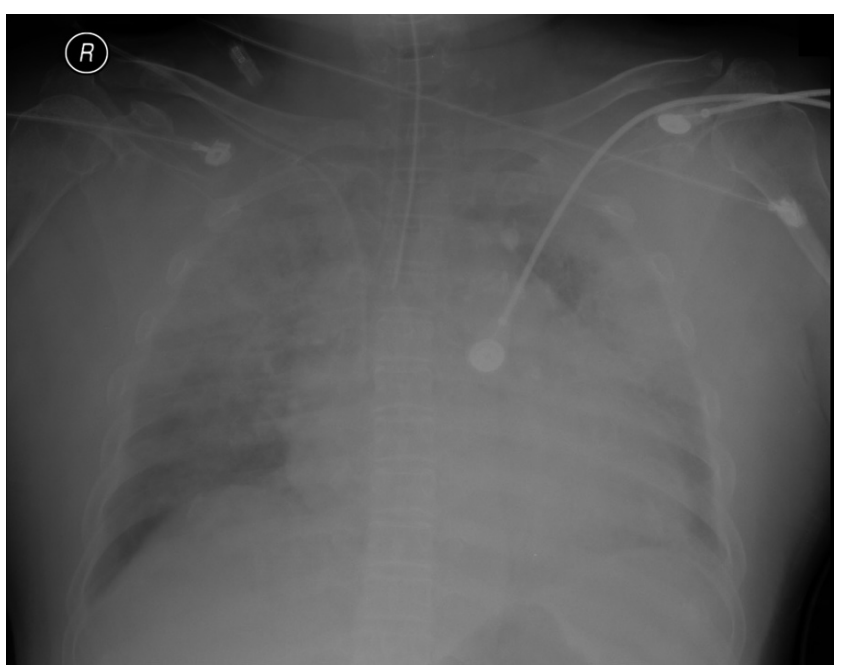

Fig. 1. The initial chest $X$-ray of this patient. It shows haziness opacities in both lungs.

computer tomography showed bilateral pleural effusion with pulmonary edema in both lungs. The echocardiography and magnetic resonance brain imaging did not showed abnormal findings to identify as cause of respiratory arrest.

Two days after admission, she progressed with acute respiratory distress syndrome (ARDS), managed with lung protective ventilator strategy, and weaned from and ECMO. On seven days of admission, ABGA showed $\mathrm{pH}$ of $7.390, \mathrm{PaCO}_{2}$ of $42.9 \mathrm{mmHg}, \mathrm{PaO}_{2}$ of $77.3 \mathrm{mmHg}$, and oxygen saturation of $94.2 \%$. Nine days after from admission, she was improved from ARDS and attempted to wean form mechanical ventilation. Since tried of weaning mechanical ventilation, she repeatedly failed to wean due to hypoventilation or hypercapnia, and occasionally she presented apnea on night. ABGA on weaning trial showed $\mathrm{pH}$ of $7.234, \mathrm{PaCO}_{2}$ of 84.9 $\mathrm{mmHg}, \mathrm{PaO}_{2}$ of $68.3 \mathrm{mmHg}$, and oxygen saturation of $85.4 \%$.

To find causes of hypoventilation and hypercapnia, she was precisely reviewed of past medical history, physical examinations, initial laboratory finding, and imaging results. The detailed medical review and new test of electroencephalogram did not show abnormal findings associated with hypoventilation and hypercapnia.

On 15 days of admission, thyroid function test showed thyroid stimulating hormone of $>100 \mu \mathrm{IU} / \mathrm{mL}$ and free thyroxine 4 of $<3.2 \mathrm{pmol} / \mathrm{L}$. She was expected to hypoventilation associated with hypothyroidism, and thyroid hormone replacement therapy (levothyroxine $50 \mu \mathrm{g}$ daily) started. On 22 days of admission, she was stable and never showed hypoventilation and hypercapnia. On 23 days of admission, she was successfully weaned from mechanical ventilation. She was diagnosed of hypothyroidism, com-

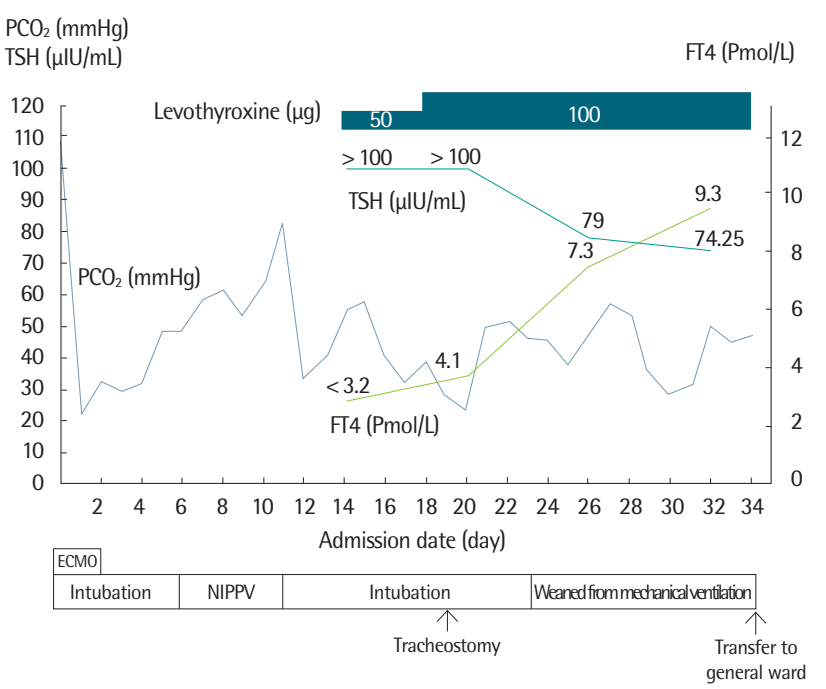

Fig. 2. A clinical course in the acute phase. FT4, free thyroxine 4; TSH, thyroidstimulating hormone; $\mathrm{PCO}_{2}$, partial pressure of $\mathrm{CO}_{2}$; NIPPV, noninvasive positive pressure ventilation; ECMO, extracorporeal membrane oxygenation.

plicating respiratory failure and weaning failure via hypoventilation. Seventy days after levothyroxine started, thyroid stimulating hormone and free thyroxine 4 was $5.54 \mu \mathrm{IU} / \mathrm{mL}$ and 11.0pmol/L. She did not present any respiratory manifestations. On 72 days of admission, she was discharge with levothyroxine $100 \mu \mathrm{g}$ maintain dose (Fig. 2).

\section{DISCUSSION}

Hypothyroidism infrequently develops respiratory manifestations affecting ventilator and neuromuscular system. Altered ventilation by hypothyroidism is explained by impaired central response to hypoxia, hypercapnia, and a propensity for respiratory alkalosis. Since Nordqvist et al. [7] had reported $\mathrm{CO}_{2}$ retention in a patient with hypothyroidism in 1960. Duranti et al. [3] identified, in 13 patients, that the ventilator control system might be altered at the neural level. Meanwhile, Lee and Levine [8] reported that respiratory alkalosis was associated with low minute ventilation in a patients with severe hypothyroidism. Decreased levels of $\mathrm{PCO}_{2}$ may trigger an adjustment in central respiratory drive [3]. In addition to altering ventilation, hypothyroidism also may cause weakness of respiratory muscles including diaphragm. Martinez et al. [4] reported that, in patients with hypothyroidism, diaphragmatic dysfunction might be occurred more frequently and could be reversed with adequate hormone replacement. And respiratory skeletal muscle mass may be lost by demyelination, fibrosis of the 
phrenic nerve, and irreversible type II fiber atrophy [6]. Sleep apnea is also complicated in patients with hypothyroidism and can manifests fatigue and dyspnea as Rajagopal et al. [1] reported obstructive sleep apnea episodes in untreated patients even with normal lung function.

Respiratory manifestations in patients with hypothyroidism can be partially improved by thyroid hormone replacement therapy. It was reported that replacement therapy normalized the response to hypercapnic and hypoxic stimulation, but not respiratory muscle strength [3]. Although Khaleeli and Edwards [6] reported that respiratory muscle dysfunction might either be permanent or take months to improve. Thyroxine therapy also decreased apnea frequency, even without change in body weight [1]. As respiratory failure due to hypothyroidism is rarely occurred, no evident or consented managements have been proposed. Behnia et al. [5] proposed an appropriate ventilator and weaning modalities based upon individual patients' needs and requirements including initial full ventilator support, including noninvasive positive pressure ventilation, and early tracheostomy in hypothyroid patients with respiratory failure.

We could find some Korean cases about respiratory failure related to hypothyroidism. They are some case report about myxedema coma [9-11]. This patient was most elderly among the reported Korean patients. And this patient was most severe state, even post arrest state and finally she has improved.

Standard therapeutic levothyroxine strategies for hypothyroidism and respiratory failure are not yet established. There are three Korean case reports: two cases were treated with low dose levothyroxine $(50 \mu \mathrm{g})$ and the other case was treated with high dose levothyroxine $(1,500 \mu \mathrm{g})$. Recently, low dose levothyroxine therapy is more preferred management. And our case was treated with low dose levothyroxine (50 mcg).

And our patient has past medical history of hypertension, diabetes mellitus, chronic heart failure, and stable angina but she did not know about hypothyroidism. So, we misinterpreted her pulmonary edema was due to heart failure. It is important that checking the thyroid function in severe respiratory failure patient even though the patient did not have hypothyroidism history. Although patients with hypothyroidism are rarely presented with respiratory failure, hypothyroidism should be considered as a possible cause, especially in cases of respiratory or weaning failure without obvious causes.

\section{REFERENCES}

1. Rajagopal KR, Abbrecht PH, Derderian SS, Pickett C, Hofeldt F, Tellis CJ, et al. Obstructive sleep apnea in hypothyroidism. Ann Intern Med 1984;101:491-4.

2. Zwillich CW, Pierson DJ, Hofeldt FD, Lufkin EG, Weil JV. Ventilatory control in myxedema and hypothyroidism. N Engl J Med 1975;292:6625.

3. Duranti R, Gheri RG, Gorini M, Gigliotti F, Spinelli A, Fanelli A, et al. Control of breathing in patients with severe hypothyroidism. Am J Med 1993;95:29-37.

4. Martinez FJ, Bermudez-Gomez M, Celli BR. Hypothyroidism: a reversible cause of diaphragmatic dysfunction. Chest 1989;96:1059-63.

5. Behnia M, Clay AS, Farber MO. Management of myxedematous respiratory failure: review of ventilation and weaning principles. Am J Med Sci 2000;320:368-73.

6. Khaleeli AA, Edwards RH. Effect of treatment on skeletal muscle dysfunction in hypothyroidism. Clin Sci (Lond) 1984;66:63-8.

7. Nordqvist P, Dhuner KG, Stenberg K, Orndahl G. Myxoedema coma and carbon dioxide-retention. Acta Med Scand 1960;166:189-94.

8. Lee HT, Levine M. Acute respiratory alkalosis associated with low minute ventilation in a patient with severe hypothyroidism. Can J Anaesth 1999; 46:185-9.

9. Park MG, Lee KJ, Lee HW, Sim EH, Kang JD, Yeo CW. Myxedema coma successfully treated by low dose oral levothyroxine. J Korean Geriatr Soc 2013;17:244-8.

10. Ahn JM, Chun JH, Kwon JW, Park SG, Koh HB, Kim JG. A case of myxedema coma treated with a large oral dose of levothyroxine. Korean J Med 2009;76(Suppl 1):S127-S30.

11. Shim JY, Lee SW, Lee HW, Choi JH, Song YJ, Lee HS, et al. A case of myxedema coma with severe hypoventilation. J Korean Soc Endocrinol 2004;19:203-8. 